\section{International Scientific Journal Theoretical \& Applied Science}

\author{
p-ISSN: 2308-4944 (print) e-ISSN: 2409-0085 (online) \\ Year: 2017 Issue: 12 Volume: 56
}

Published: $19.12 .2017 \quad \underline{\text { http://T-Science.org }}$
Julia Igorevna Zelenova

Graduate student

Russian State University named after A.N. Kosygin

(Technology. Design. Art), Russia zelenova.julie@yandex.ru

Valeriy Savelievich Belgorodskiy

Doctor of Sociology, Professor

Russian State University named after A.N. Kosygin

(Technology. Design. Art), Russia

SECTION 15. Decorative and fine arts.

\title{
TRADITIONAL PROTOTYPES TECHNOLOGY LACE
}

Abstract: Innovative developments in the textile industry always have an underlying cause in the form of authentic prototypes, which represent the conventional technology. This base element defines the development of innovative solutions in the field of technological and engineering developments. As a result, and the necessity of saving the national craft technologies that are at the same time and the factor of self-identification of peoples, and the inexhaustible source of innovation.

Key words: authentic technology, tradition, lace, nubby weave, openwork embroidery, macrame, transformation, innovation.

Language: Russian

Citation: Zelenova JI, Belgorodskiy VS (2017) TRADITIONAL PROTOTYPES TECHNOLOGY LACE. ISJ Theoretical \& Applied Science, 12 (56): 5-9.

Soi: http://s-o-i.org/1.1/TAS-12-56-2 Doi: crossef https://dx.doi.org/10.15863/TAS.2017.12.56.2

\section{УДК 745:687.1}

\section{ТРАДИЦИОННЫЕ ПРОТОТИПЫ ТЕХНОЛОГИИ КРУЖЕВОПЛЕТЕНИЯ}

Аннотация: Инновационные разработки в текстильной промышленности всегда имеют подоснову в виде аутентичных прототипов, которые представляют собой традиционные технологии. Этот базисный первоэлемент определяет направление развития новаторских решений в сфере технологоконструкторских разработок. Вследствие чего, и определяется необходимость сбережения национальных ремесленно-промысловых технологий, являюшихся в то же время и фактором самоидентификации народов, и неиссякаемым источником для инноваций.

Ключевые слова: аутентичные технологии, традиции, кружево, узелковое плетение, ажурное иитье, макраме, трансформачия, инновачии.

\section{Introduction}

В современном мире текстильная промышленность ориентирована на использование технологических инноваций в системе производства, что позволяет улучшить динамику экономического роста и конкурентоспособность. Сам термин «инновация», введеный в 1930-х гг. австрийским ученым Шумпетером, в данном контексте подразумевает внедренное нововведение, включающее новые технологические продукты и новые процессы их производства [1]. Новые промышленные разработки широко применяются в коллекциях сегмента прет-а-порте.

Параллельно с интенсификацией производства прет-а-порте, такие ведущие модные бренды, как Шанель, Диор, Александр Маккуин, Оскар де ла Рента и др. продолжают развивать сегмент от кутюр, в котором используют и традиционные ручные технологии, способствующие обогащению образного восприятия костюмов, повышению их моральной ценности для потребителя.

\section{Materials and Methods}

Визуальное сходство в коллекциях различных по исполнению ручных техник с кружевом указывает на их единое происхождение. Еще с первобытных времен развивалось два основных вида технологий: узелковое плетение и вышивка, предваряющих появление утонченного искусства кружевоплетения в Италии в XV веке [2, с. 96]. На протяжении нескольких столетий эти виды ремесленных технологий, совместно с кружевоплетением, продолжают развиваться, не 
теряя актуальности применения как в костюме, так и в интерьере.

Техника узелкового плетения «макраме» (от арабск. «миграмах» - тесьма, кружево, от турецк. «макрама» - шарф с бахромой) известна более 4-х тысяч лет. В культурах Китая, Японии и индейцев Северной Америки эта техника появилась в виде системы узелковой письменности, как способ накопления и передачи информации из поколения в поколение.

В IX в. до н.э. простейшее узелковое плетение в виде ромбовидной решетки филе (фр. filet - сеточка) использовалось для плетения рыболовных и охотничьих сетей. С развитием мореплавания вязание сложных морских узлов было абсолютной необходимостью для надежного крепления тросов корабля. Некоторые виды морских узлов и стали прообразами для плетения макраме.

В XVII-XVIII веках макраме обрело большую популярность в Англии и Северной Европе в качестве декора интерьера. Этот досуг считался увлечением знатных дам и королевских особ. Мария Медичи, королева Франции, в 1600 году обучалась искусству макраме в Голландии, а Шарлотта Мекленбург-Стрелицкая, жена британского короля Георга III, своими руками выплела кайму для декорирования изгороди во внутреннем королевском дворике.

Французский термин «макраме» (macramé) был закреплен в истории рукоделий, благодаря созданию энциклопедии «Полный курс женских рукоделий» (1884 г.) Терезой Дильмон. Вся вторая половина XIX века ознаменована повсеместным увлечением техникой плетения макраме наравне с кружевоплетением, которая является синтезом «филе» и «морских узлов». Ее особенностью является использование грубых плотно скрученных нитей без дополнительных инструментов.

В настоящее время известные модные бренды, используя технику макраме, демонстрируют на подиумах множество моделей костюмов и в стиле «фолк» (фольклорный) Марк Фаст (рис. 1 а), Гуччи, и в стиле «футуризм» - Элеанор Аморосо (рис. 1 б), Мартин Марджела, Кирилл Минцев.

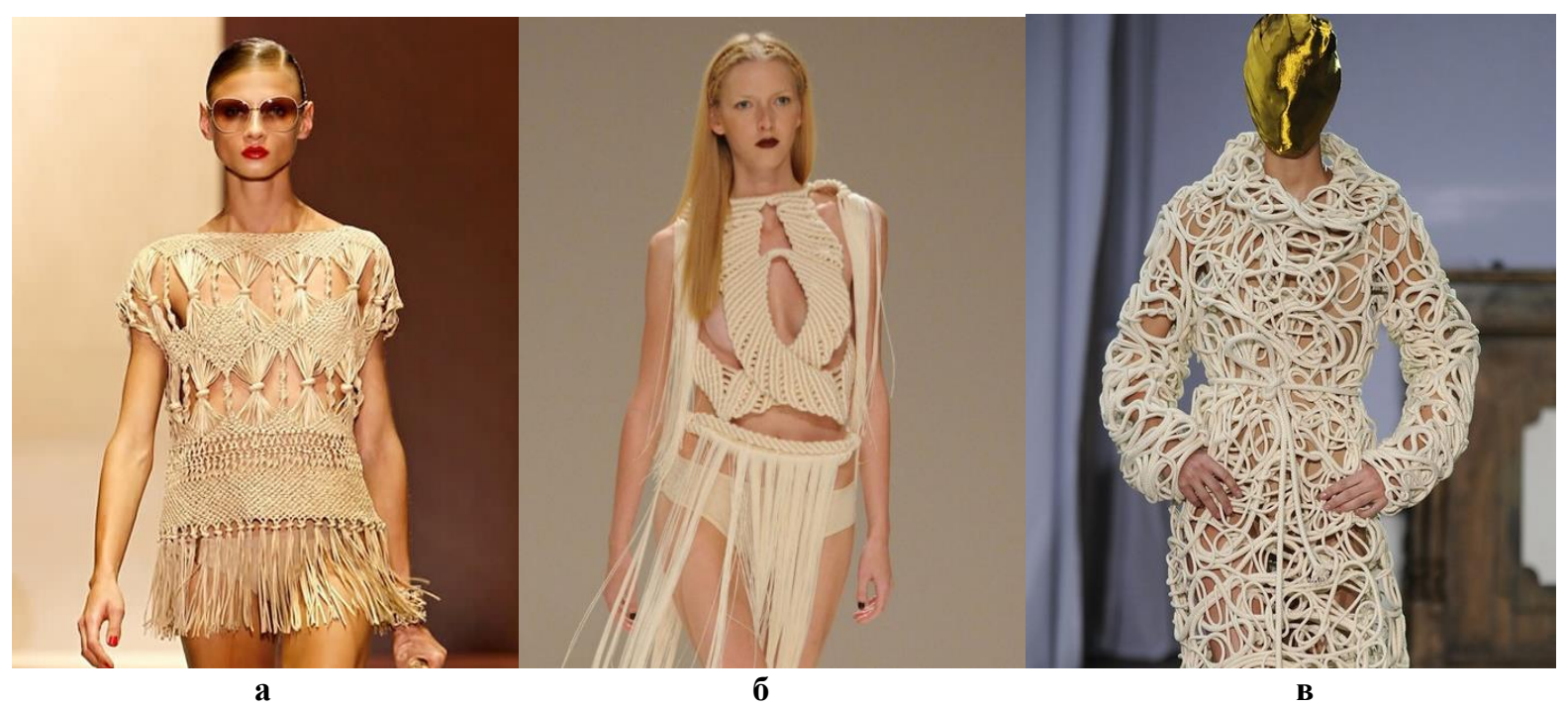

Рисунок 1 - Использование техники макраме в коллекциях знаковых дизайнеров: а - Марк Фаст; б - Элеанор Аморосо; в - Мартин Марджела

Одним из первых утонченных видов декора костюма является вышивка. В качестве отделки одежды высших сословий вышивка использовалась еще в Древнем Египте, Древней Греции и Риме, что подтверждают археологические находки: вышитые куски древнеегипетской материи (С.- Пб. Эрмитаж) и статуя Дианы из города Портичи (Италия), цветная роспись одежд которой напоминает вышивку [3].
Парадные одежды русских князей, бояр и духовенства богато расшивались золотосеребряной канителью по византийской моде. Вышивка льняных крестьянских рубах, преимущественно красной нитью, по вороту и краям рукавов приобретала магическую функцию защиты от порчи и «дурного глаза». Иглы для вышивания в этот временной период, до усовершенствования ковки в XV веке, и 
натуральные нити были достаточно грубые, поэтому вышивка имела плотную структуру.

Ажурное шитье по полотну, напрямую предшествующее кружеву, является разновидностью вышивки [4, с. 45]. Традиционно это шитье белыми нитями с продергиванием нитей основы или утка ткани (остаются ажурные ровные линии) [5, с. 490]. Такой вид шитья используется для декорирования льняных полотен, сотканных из толстых нитей еще со времен европейского Средневековья.

У славянских народов шитье с продергиванием нитей полотна называется «прошва» или «мережка» (рис. 2). Оно имело большую популярность у крестьян в отделке льняных рубах, постельного и столового белья.

Вышивка «мережка» развивалась во всем мире наравне с другими видами рукоделия, как замена дорогостоящему кружеву. Но в первой половине XX века из-за затяжных войн были утрачены многие рукотворные ремесла.

Начиная со второй половины XX века и до настоящего времени изысканность ажурного шитья способствует привлечению художников к этому виду искусства и его совершенствованию.

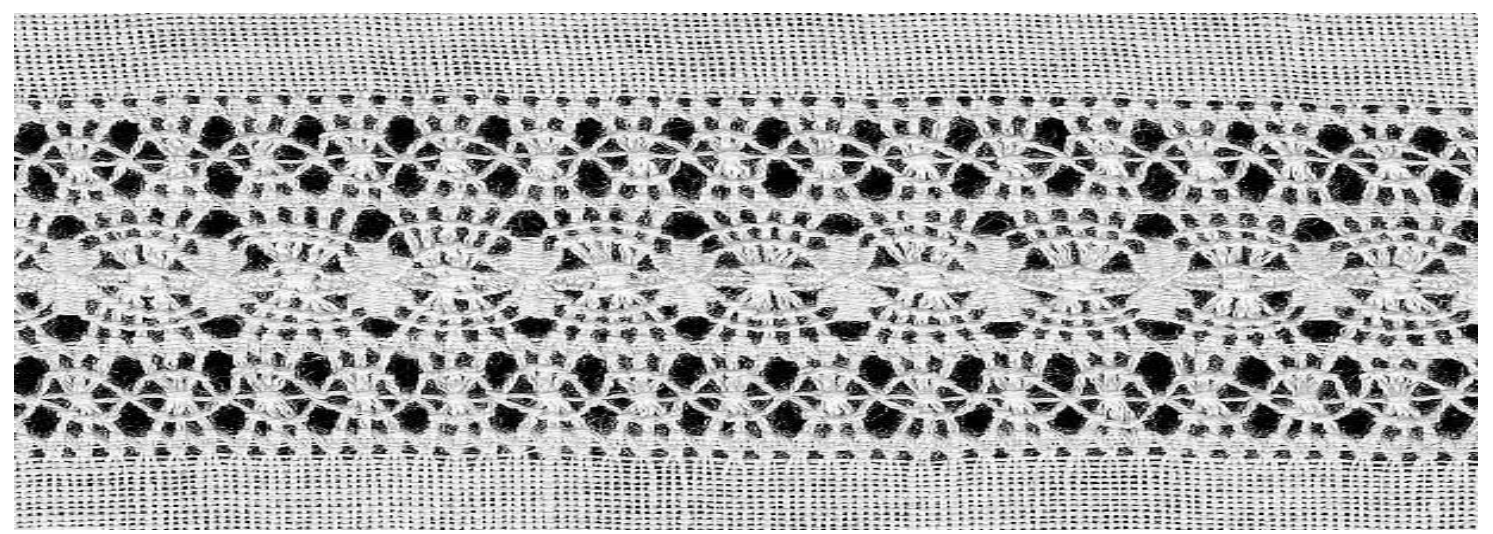

Рисунок 2 - Мережка.

Рассмотренные в статье виды декорирования костюма и предметов быта предопределяют и способствуют появлению еще одного нового более сложного вида декоративноприкладного искусства — кружевоплетения. На рис. 3 представлена трансформация традиционных технологий во времени, от которых берут начало две основных технологии кружевоплетения. В конечном итоге от вышивки зародилось игольное кружево «punto in aria» (с итал. стежок в воздух) [6, с. 22], а от техники узелкового плетения - коклюшечное плетеное кружево. Благодаря развитию данного ремесла в различных европейских странах (Италия, Франция, Испания, Англия, Бельгия, Австрия, Германия, Голландия) и России, кружево на данный момент насчитывает более 10 разновидностей по технике исполнения (ирландское, вязанное крючком, фриволите и пр.), многие из которых получили свое название от кружевных городов-мануфактур, привнесших в его ажурный орнамент свою культурную самобытность: алансонские кружева (Франция, Алансон), брюггские кружева (Бельгия, Брюгге), вологодские кружева (Россия, Вологда), елецкие кружева (Россия, Елец) и др [7, с.96]. 


\begin{tabular}{|c|c|c|c|c|c|c|}
\hline Impact Factor: & $\begin{array}{l}\text { ISRA (India) } \\
\text { ISI (Dubai, UAE } \\
\text { GIF (Australia) } \\
\text { JIF }\end{array}$ & $\begin{array}{r}=1.344 \\
=0.829 \\
=0.564 \\
=1.500\end{array}$ & $\begin{array}{l}\text { SIS (USA) } \\
\text { PИНЦ (Russia) } \\
\text { ESJI (KZ) } \\
\text { SJIF (Morocco) }\end{array}$ & $\begin{array}{l}=0.912 \\
=0.207 \\
=4.102 \\
=2.031\end{array}$ & $\begin{array}{l}\text { ICV (Poland) } \\
\text { PIF (India) } \\
\text { IBI (India) }\end{array}$ & $\begin{array}{l}=6.630 \\
=1.940 \\
=4.260\end{array}$ \\
\hline
\end{tabular}

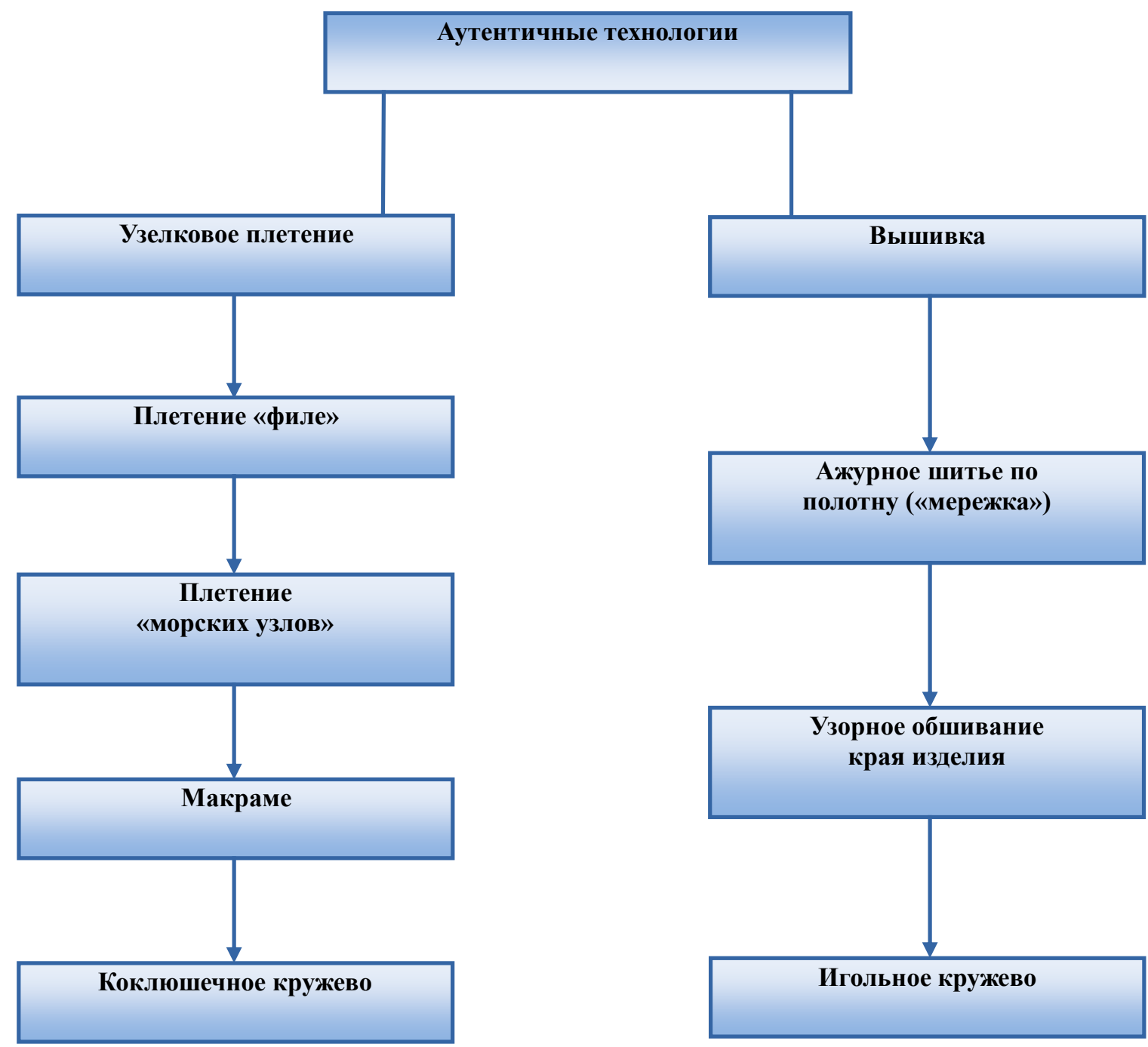

Рисунок 3 - Трансформация традиционных технологий декорирования.

Имея эстетическую особенность, способствующую обогащению образно-стилевого решения костюма, кружево и его подлинные прототипы приобрели необыкновенную популярность не только в Евразии, но и во всем мире. К примеру, существует бразильское кружево «соль» (солнечное кружево или Тенерифе, рис. 4) и мексиканское кружево (макраме), которое укоренилось в этих странах вследствие проникновения кружева и плетения макраме из Европы во время морских экспедиций.

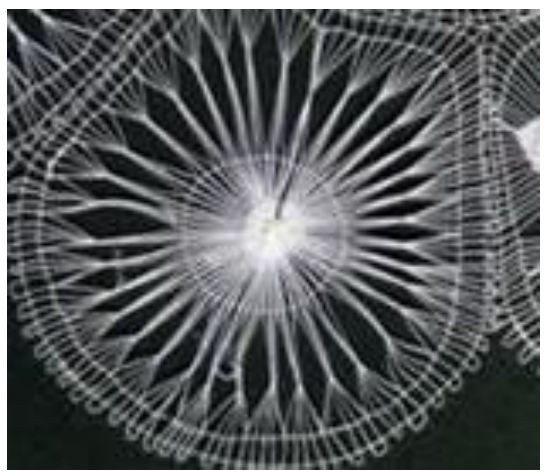

Рисуно 4 - Кружево Тенерифе (страна происхождения - Испания)

ISPC Generalization of scientific results,

Philadelphia, USA 


\begin{tabular}{l|lr|ll|ll} 
& ISRA (India) & $=\mathbf{1 . 3 4 4}$ & SIS (USA) & $=\mathbf{0 . 9 1 2}$ & ICV (Poland) & $=\mathbf{6 . 6 3 0}$ \\
Impact Factor: & ISI (Dubai, UAE) $=\mathbf{0 . 8 2 9}$ & PUHЦ (Russia) $=\mathbf{0 . 2 0 7}$ & PIF (India) & $=\mathbf{1 . 9 4 0}$ \\
& GIF (Australia) & $\mathbf{0 . 5 6 4}$ & ESJI (KZ) & $=\mathbf{4 . 1 0 2}$ & IBI (India) & $=\mathbf{4 . 2 6 0}$ \\
& JIF & $=\mathbf{1 . 5 0 0}$ & SJIF (Morocco) & $=\mathbf{2 . 0 3 1}$ & & \\
\hline
\end{tabular}

Кружево является самой тонкой синтетической технологией плетения и шитья. Распространившись по всему миру в качестве отделки одежды и жилого пространства, оно обрело статус всемирного достояния, благодаря бережному сохранению традиционных технологий и их совершенствованию, а также совершенствованию художественного уровня изделий, выполненных с помощью данных технологий. Классическое кружево - это плоскостной вариант существования ниточного переплетения, зародившееся от объемного плетения и вышивки — из многомерного наложения нитей и объемных узлов и грубых плетений в самый тонкий слой ажурного полотна [8, с.123]. От простого декора - к символизму и знаковости в костюме [9, с. 94], где кружево является первым определяющим элементом хорошего вкуса и аристократического статуса.

\section{Conclusion}

Традиции являются основополагающим фундаментом для развития технологий и разработки инноваций. К примеру, кружево послужило прототипом для первых печатных структур при помощи 3D-принтера. Таким образом, без учета традиционных технологий и их сохранения развитие инноваций станет нецелесообразно, так как инновации и создаются как способ улучшения эстетических характеристик изделий, создаваемых с помощью аутентичных технологий, и как способ интенсификации данного производства. Ежи Шацкий в своей книге «Утопия и традиция» отмечал такую особенность диалектизма традиций и инноваций: «Традиция живет только обновляясь, а у новации нет другого способа выжить, как доказать свою органичность, укорененность в культуре и добиться статуса традиции, выработать механизм взаимной адаптации традиции в конкретном месте и времени» [10] .

\section{References:}

1. Zaytsev AV (2014) Osobennosty funkcionirovaniya visokotechnologichnogo predpriyatiya $\mathrm{v}$ innovatsionnoy economike // Voprosy innovatsionnoy economiki T. 4 (1), p. 21-35.

2. Lorentsa NF (1898) Ornament vseh vremen I stiley. 100 tablic s obyasnitelnym tekstom. Spb. Izdanie AF.

3. Davydova SA. Russkoe krujevo I krujevnitsy [Elektronny resurs] Available: http://www.booksite.ru/fulltext/davyi/dova/ (Accessed: 10.12.2017).

4. 4.Popova OS, Koroleva NS, Chirkov DA, Kaplan NI, Rabotnova IP, Fedotova LV (1984) Narodnye chudojestvennye promysly. Pod obsh.red. Popovoy OS. Moskva "Legkaya I pichevaya promyshlennost",, p. 192.

5. Dilmon $\mathrm{T}$ (2003) Polnaya enciklopediya jenskich rukodeliy / Per. Avdoninoy $\mathrm{M}$, Botvinko U, Moskva: Eksmo, p. 736.

http://bibliofond.ru/view.aspx $? \mathrm{id}=813228$
6. Zolotye veka italyanskogo krujeva: muzeyniy katalog (24 noyabr. 2011 - 10 janv. 2012, Moskva) / redkol. Valter Kapeccali, Italia: Leticia Pinyani, 2011, p. 196.

7. Belgorodskiy VS (2010) Innovatsii v materialach industrii mody: ushebnoe posobie / Belgorodskiy VS, Kirsanova EA, Gicharev AP, Moskva: IITS MGUDT, p. 113.

8. Kirsanova EA, Zvyagintsev SV (2008) Dizayn otdelki shveynich izdeliy, monografiya, Moskva: IITS MGUDT, p. 192.

9. . Belgorodskiy VS, Zelenova JI (2017) Obrazno-assotsiativniy metod $\mathrm{v}$ proektirovanii krujevnych motivov. Sovremennye gumanitarnye issledovaniya. N.3 (76), p. 94-98.

10. Russkiy narodniy kostyum v sovremennom mire mody [Elektronny resurs] Available: http://bibliofond.ru/view.aspx?id=813228 (Accessed: 10.12.2017). 